\title{
PENGEMBANGAN MODEL PERMAINAN TRADISIONAL GEPREK KEMPUNG DAN GOBAG SODOR UNTUK PEMBELAJARAN ILMU PENGETAHUAN SOSIAL DI SEKOLAH DASAR
}

\author{
Mohammad Toha \\ Universitas Negeri Malang, Jalan Semarang 5 Malang 65145 \\ E-mail: aatoha_266@yahoo.com
}

\begin{abstract}
The subjects of Social Science (IPS) close to the environment. Therefore, IPS learning, especially at the elementary level (SD), should optimally utilize the potential of the environment as a source of learning, so that learning becomes more meaningful. The general objective of this research is to produce an effective and innovative model of IPS SD learning model by utilizing existing learning resources in the traditional game-based environment. The specific purpose of this research is to produce the product of the traditional game model of geprek kempung and gobag sodor for IPS class IV learning material of Developing Production Technology and Communication, which is equipped with lesson plan (RPP), guidebook and media of both games. This research and development adopts Borg and Gall modified theories into five stages: (1) preliminary study; (2) developing the initial product; (3) expert validation and revision; (4) small-scale field trials and product revisions; and (5) large-scale field trials and final product revisions. To measure the effectiveness of the product used data collection instruments in the form of questionnaire assessment and test results learning. The results showed that the traditional game model geprek kempung and gobag sodor effectively implemented in learning learning.
\end{abstract}

Keywords: learning model, traditional game, geprek kempung, gobag sodor, social science

\begin{abstract}
Abstrak: Mata pelajaran Ilmu Pengetahuan Sosial (IPS) dekat dengan lingkungan. Oleh karena itu, pembelajaran IPS khususnya di tingkat sekolah dasar (SD), harus memanfaatkan secara optimal potensi lingkungan sebagai sumber belajar, agar pembelajaran menjadi lebih bermakna. Tujuan umum penelitian ini untuk menghasilkan sebuah produk model pembelajaran IPS SD yang efektif dan inovatif dengan memanfaatkan sumber belajar yang ada di lingkungan sekitar berbasis permainan tradisional. Tujuan khusus penelitian ini menghasilkan produk berupa model permainan tradisional geprek kempung dan gobag sodor untuk pembelajaran IPS kelas IV materi Perkembangan Teknologi Produksi dan Komunikasi, yang dilengkapi dengan RPP, buku panduan dan media kedua permainan tersebut. Penelitian dan pengembangan ini mengadopsi teori Borg dan Gall yang dimodifikasi menjadi lima tahapan, yakni: (1) studi pendahuluan; (2) mengembangkan produk awal; (3) validasi ahli dan revisi; (4) uji coba lapangan skala kecil serta revisi produk; dan (5) uji coba lapangan skala besar dan revisi produk akhir. Untuk mengukur efektifitas produk digunakan instrumen pengumpulan data berupa angket penilaian dan tes hasil belajar. Hasil penelitian menunjukkan bahwa model permainan tradisional geprek kempung dan gobag sodor efektif dilaksanakan dalam pembelajaran pembelajaran.
\end{abstract}

Kata kunci: model pembelajaran, permainan tradisional, geprek kempung, gobag sodor, IPS

Guru sebagai agen pembelajar harus mampu menyajikan pembelajaran secara kontektual dengan melibatkan langsung peranserta siswa secara aktif (student centre). Untuk itulah guru harus mampu meramu pembelajaran menjadi menarik, efektif, inovatif, termasuk dalam membuat dan memanfaatkan model pembelajaran.
Dengan menggunakan model pembelajaran yang tepat akan tercipta suasana belajar yang tenang dan menyenangkan (enjoyable learning), sehingga mendorong pembelajaran aktif, keratif, efektif, dan bermakna. Kondisi belajar yang demikian akan mendorong siswa untuk belajar mengetahui (learning to know), belajar berkarya (learning to 
do), belajar menjadi diri sendiri (learning to be) dan belajar untuk hidup bersama orang lain secara harmonis (learning to live together). Oleh karena itu, setiap saat guru-guru harus selalu meningkatkan mutu pembelajaran (effective teaching) untuk semua mata pelajaran, termasuk pelajaran Ilmu Pengetahuan Sosial (IPS).

Menjadi kajian yang unik yakni dengan menelaah dan mencari makna yang terkandung dalam permainan tradisional (Gunawan, 2016; Gunawan dan Sulistyoningrum, 2013). Permainan merupakan alat yang sangat baik untuk mengembangkan aspek sosial dan moral anak, karena ada aturan-aturan tertentu yang harus diikuti semua anak (Gunawan, 2016; Gunawan, 2012). Jika permainan menjadi lebih terorganisasi dan aturan-aturan dapat diterapkan, maka anak belajar memodifikasi perilakunya untuk menghormati yang lain dan memahami batas-batas sosial (Gunawan, 2016; Gunawan dan Sulistyoningrum, 2013). Jika anak matang, maka ia makin sadar mengenai kebutuhan kerja tim. Beberapa permainan yang lebih kompleks memerlukan kerja kognitif untuk mengembangkan strategi yang sederhana (Hidayatullah, 2008). Berkaitan dengan peran pendidik dalam proses pembelajaran, maka diperlukan metode-metode untuk mengembangkan sosial emosi anak salah satunya yaitu dengan bermain (Gunawan, 2016; Gunawan, 2012). Bermain adalah salah satu upaya yang dapat dilakukan oleh pendidik untuk mengembangkan sosial emosi anak (Gunawan, 2016; Gunawan dan Sulistyoningrum, 2013).

Beberapa alasan mengambil permainan geprek kempung dan gobag sodor untuk dikembangkan, adalah pertama, di dalam kedua permainan tersebut terdapat nilai-nilai kompetitif, kooperatif, dan hiburan. Kompetitif dikarenakan dalam permainan ini ada dua regu saling mengadu ketangkasan untuk berusaha menjadi pemenang. Kooperatif, semua anggota kelompok saling bekerjasama dalam permainan. Hiburan, dikarenakan selama permainan berlangsung, suasana gembira menyelimuti jiwa anak-anak. Kedua, banyak sisi positif yang terkandung dari kedua permainan tersebut, di antaranya melatih perkembangan psikomotorik, kognitif, keseimbangan, komunikatif, dan lain sebagainya, sehingga bermanfaat untuk perkembangan jiwa anak. Ketiga, yang tidak kalah penting, kedua permainan tersebut adalah produk asli mainan Indonesia, sehingga merupakan salah satu aset budaya asli Indonesia yang perlu untuk dilestarikan.

\section{METODE}

Model penelitian dan pengembangan yang digunakan dalam pengembangan model permainan geprek kempung dan gobag sodor untuk pembelajaran IPS Kelas IV SD ini diadaptasi dari prosedur model penelitian dan pengembangan yang ditulis oleh Borg dan Gall (1983). Model ini dipilih karena cocok untuk mengembangkan dan memvalidasi produk pendidikan. Implementasi pengembangan model permainan tradisional geprek kempung dan gobag sodor memodifikasi langkah-langkah penelitian dan pengembangan Borg dan Gall (Gambar 1).

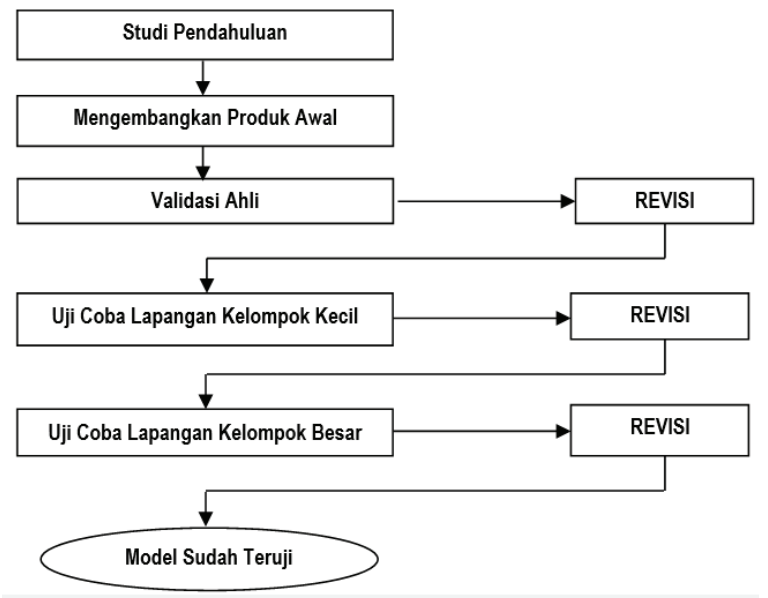

\section{Gambar 1 Prosedur Penelitian dan} Pengembangan

\section{HASIL}

Produk pengembangan yang diujicobakan adalah berupa model permainan geprek kempung dan gobag sodor untuk pembelajaran IPS SD yang dituangkan dalam bentuk Rencana Pelaksanaan Pembelajaran (RPP), dilengkapi dengan buku pedoman permainan dan perangkat alat (media) permainan geprek kempung dan gobag sodor. Model permainan ini mengacu pada buku panduan yang telah divalidasi oleh ahli desain model pembelajaran dan ahli materi IPS. Dari hasil beberapa kali penilaian dan validasi, selanjutnya dilakukan beberapa kali revisi sampai akhirnya dapat disetujui oleh Validator ahli sebelum diuji 
cobakan ke lapangan. Berikut ini diuraikan gambaran situasi dan langkah-langkah permainan yang telah dikembangkan.

\section{Permainan Geprek Kempung}

Permainan geprek kempung diilustrasikan pada Gambar 2.

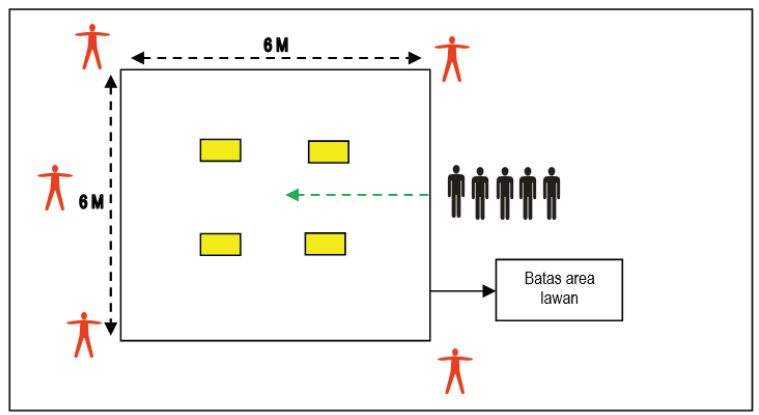

Gambar 2 Situasi Permainan Gaprek Kempung

Keterangan:

: Tempat tumpukan koin jawaban

$\square$ : Papan soal

$\rightarrow$ : Arah lemparan ke tumpukan koin

i : Regu main

\ : Regu lawan

Berikut ini diuraikan deskripsi dari permainan geprek kempung yang dikembangkan:

a. Alat permainan yang digunakan

Alat yang digunakan adalah: (1) papan soal yang terbuat dari triplek dengan ukuran $20 \mathrm{~cm}$ x $40 \mathrm{~cm}$ (Gambar 3); (2) koin jawaban terbuat dari triplek tebal dengan ukuran diameter $8 \mathrm{~cm}$ (Gambar 3); (3) bola tenis; dan (4) kapur/lakban untuk membuat garis lapangan.
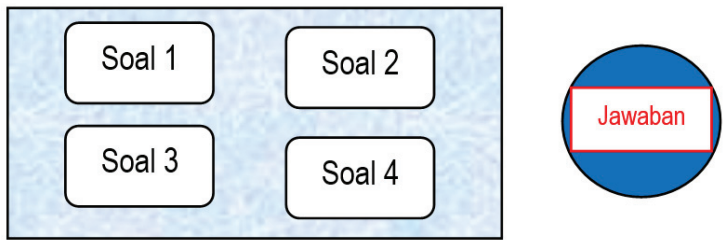

Gambar 3 Papan Soal dan Koin Jawaban Permainan Geprek Kempung

b. Keterlibatan siswa dalam permainan: dilakukan secara berkelompok, setiap kelompok \pm 5 orang (dikondisikan dengan jumlah siswa)

c. Waktu permainan: 10 Menit

d. Langkah-langkah permainan:
Guru menyampaikan kompetensi yang ingin dicapai. Guru menyampaikan materi secukupnya atau siswa disuruh membacakan buku atau modul dengan waktu secukupnya. Guru membentuk grup yang anggotanya \pm 5 orang (disesuaikan dengan jumlah siswa) secara heterogen dan mengasih nama grup dengan nama-nama daerah atau sesuai topik materi pelajaran. Guru membacakan aturan permainan dan mengundi grup yang akan bertanding. Guru meletakkan koin jawaban secara bertumpuk di tengah lapangan. Grup yang giliran main melemparkan bola ke arah tumpukan koin. Jika tidak mengenai sasaran maka diteruskan oleh peserta berikutnya dan jika sampai habis anggota grup main tidak ada yang mengenai sasaran (tumpukan koin), maka permainan diambil alih oleh grup lawan. Jika tumpukan koin berhasil dirubuhkan, maka anggota grup main segera mencocokan koin jawaban yang berserakan sesuai kolom soal, sambil menghindari tembakan bola dari grup lawan. Grup yang giliran jaga (grup lawan) berusaha mengganggu grup main dengan cara bekerjasama menembakan bola agar semua orang di grup main gugur dan gagal mencocokan koin jawaban ke kolom soal.

Bola tidak boleh dibawa lari, tetapi harus dioper ke teman lainnya. Hindari menembak ke arah kepala dan bagian tubuh yang vital dan tidak boleh melewati batas area lawan. Anggota grup main yang terkena lemparan bola, maka secara otomatis dia gugur dan harus keluar arena permainan. Permainan dinyatakan selesai apabila durasi waktu permainan habis, soal sudah terjawab semua, dan anggota grup main telah gugur semua. Sistem penilaiannya adalah: (1) siswa yang menjawab benar akan mendapatkan poin berupa bintang berwarna dengan poin 100 dan jika menjawab salah akan mendapatkan bintang putih dengan poin 25 ; siswa yang yang menyelesaikan permainan tepat waktu mendapat poin 100; untuk menghitung perkembangan skor individu dihitung sebagaimana dapat dilihat pada Tabel 1; dan (2) skor kelompok dihitung dengan membuat ratarata skor kelompok, yaitu dengan menjumlahkan semua skor individu anggota kelompok dan membagi sejumlah anggota kelompok tersebut, sesuai dengan rata-rata skor kelompok, diperoleh skor kelompok sebagaimana dalam Tabel 2. 
Tabel 1 Penghitungan Skor Individu

\begin{tabular}{clll}
\hline No & \multicolumn{1}{c}{ Kriteria } & \multicolumn{1}{c}{ Keterangan } & Nilai \\
\hline 1 & $\begin{array}{l}\text { Siswa yang menyelesaikan } \\
\text { permainan tepat waktu }\end{array}$ & Mendapat & Nilai 100 \\
2 & Setiap jawaban yang benar & Mendapat & Nilai 100 \\
3 & Setiap jawaban yang salah & Mendapat bintang putih & Nilai 25 \\
\hline
\end{tabular}

Tabel 2 Penghitungan Skor Kelompok

\begin{tabular}{cll}
\hline No & Rata-rata Skor & \multicolumn{1}{c}{ Kualifikasi } \\
\hline 1 & $0 \leq \mathrm{N} \leq 50$ & Tim yang Belum Berhasil \\
2 & $60 \leq \mathrm{N} \leq 150$ & Tim yang Baik (Good Team) \\
3 & $160 \leq \mathrm{N} \leq 200$ & Tim yang Baik Sekali(Great Team) \\
4 & $210 \leq \mathrm{N} \leq 300$ & Tim yang Istimewa (Super Team) \\
\hline
\end{tabular}

\section{Permainan Gobag Sodor}

Permainan gobag sodor diilustrasikan pada Gambar 4.

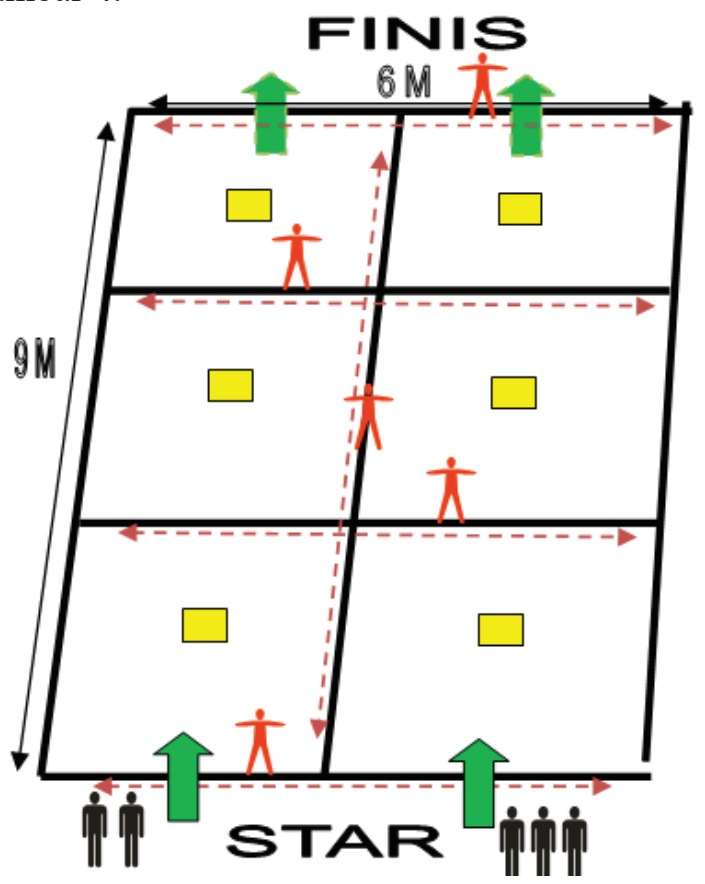

Gambar 4 Situasi Permainan Gobag Sodor

Keterangan:

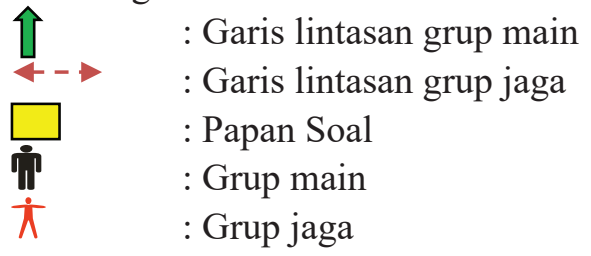

Berikut ini diuraikan deskripsi dari permainan gobag sodor yang dikembangkan:

a. Alat permainan yang digunakan

Alat yang digunakan adalah: (1) papan soal yang terbuat dari triplek dengan ukuran $20 \mathrm{~cm} \mathrm{x}$
$40 \mathrm{~cm}$ (Gambar 5); (2) kartu jawaban terbuat dari kertas asturo dengan ukuran $3 \mathrm{~cm}$ x $10 \mathrm{~cm}$ (Gambar 5); dan (3) kapur untuk membuat garis lapangan.

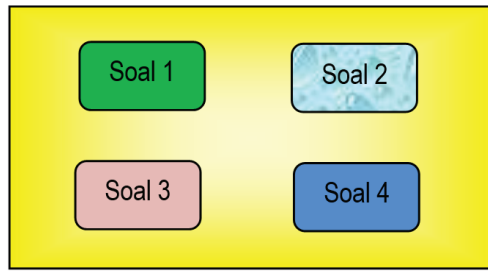

Jawaban

\section{Gambar 5 Papan Soal dan Kartu Jawaban Permainan Gobag Sodor}

b. Keterlibatan siswa dalam permainan dilakukan secara berkelompok, setiap kelompok 5 orang

c. Waktu Permainan: 10 Menit

d. Langkah-langkah permainan:

Guru menyampaikan kompetensi yang ingin dicapai. Guru menyampaikan materi secukupnya atau siswa disuruh membacakan buku atau modul dengan waktu secukupnya. Guru membentuk grup yang anggotanya 5 orang secara heterogen prestasi, jenis kelamin, ras. Guru membuat bagan pertandingan dan mengundi tiap grup yang akan bertanding. Sebelum permainan dimulai, guru membagikan 4 kartu jawaban kepada masing-masing anggota grup yang giliran main. Setiap orang di grup jaga, membuat penjagaan berlapis dengan cara berbaris ke belakang sambil merentangkan tangan agar tidak dapat dilalui oleh lawan. Satu orang penjaga lagi bertugas di garis tengah yang bergerak tegak lurus dari penjaga lainnya. Guru meniup pluit tanda permainan dimulai, anggota grup yang giliran main, berusaha masuk ke arena lapangan dengan menghindari 
hadangan grup jaga. Anggota grup main yang berhasil masuk arena permainan harus menjawab pertanyaan yang telah disediakan dengan cara menempelkan kertas jawaban. Selama permainan berlangsung, salah satu kaki penjaga harus tetap di atas garis jaga. Jadi, ia tidak bisa bergerak bebas untuk menghalangi pemain lawan melaluinya.

Jika pemain tersentuh oleh penjaga, maka secara otomatis ia gugur dan langsung keluar arena, tetapi permainan tetap diteruskan selagi masih ada teman-temannya yang belum gugur untuk menyelesaikan misi permainan. Permainan dinyatakan selesai apabila durasi waktu permainan habis, soal sudah terjawab semua, dan anggota grup main telah gugur semua. Sistem penilaian adalah: (1) siswa yang menjawab benar akan mendapatkan poin berupa bintang berwarna dengan poin 100 dan jika menjawab salah akan mendapatkan bintang putih dengan poin 25 , siswa yang menyelesaikan permainan tepat waktu mendapat poin 100 , untuk menghitung perkembangan skor individu dihitung sebagaimana dapat dilihat pada Tabel 3; dan (2) skor kelompok dihitung dengan membuat ratarata skor kelompok, yaitu dengan menjumlahkan semua skor individu anggota kelompok dan membagi sejumlah anggota kelompok tersebut, sesuai dengan rata-rata skor kelompok, diperoleh skor kelompok sebagaimana dalam Tabel 4.

\section{Uji Coba Lapangan Kelompok Kecil}

Hasil tanggapan siswa terhadap model permainan tradisional geprek kempung dan gobag sodor pada uji coba kelompok kecil secara umum mendapatkan respons yang positif, yakni 92,85\% menjawab sangat menarik belajar IPS dengan menggunakan model permainan tradisional geprek kempung maupun gobag sodor. Hal ini berimplikasi pada tingkat pemahaman siswa terhadap konsep materi IPS yang disampaikan melalui kedua model permainan tersebut, yakni $88,09 \%$ siswa menjawab sangat mudah. Adapun tingkat kerumitan soal pada permainan geprek kempung dan gobag sodor menurut siswa, $85,72 \%$ menjawab sangat mudah, sedangkan 14,28\% menjawab mudah.

Kejelasan gambar dan tulisan dalam media permainan $83,33 \%$ siswa menjawab sangat jelas. Selanjutnya, tingkat kejelasan soal yang digunakan pada kedua permainan tersebut, 76,19\% siswa menjawab sangat jelas. Terakhir tanggapan siswa terhadap teknik permainan geprek kempung dan gobag sodor, $83,33 \%$ siswa menjawab sangat mudah dimainkan. Hasil jawaban/respons siswa terhadap masing-masing aspek penilaian model permainan geprek kempung dan gobag sodor. Secara keseluruhan gambaran jawaban siswa terhadap model permainan geprek kempung dan

Tabel 3 Penghitungan Skor Individu

\begin{tabular}{clll}
\hline No & \multicolumn{1}{c}{ Kriteria } & \multicolumn{1}{c}{ Keterangan } & \multicolumn{1}{c}{ Nilai } \\
\hline 1 & Siswa yang menyelesaikan permainan tepat waktu & Mendapat & Nilai 100 \\
2 & Setiap jawaban yang benar & Mendapat & Nilai 100 \\
3 & Setiap jawaban yang salah & Mendapat bintang putih & Nilai 25 \\
\hline
\end{tabular}

Tabel 4 Penghitungan Skor Kelompok

\begin{tabular}{cll} 
No & \multicolumn{1}{c}{ Rata-rata Skor } & \multicolumn{1}{c}{ Kualifikasi } \\
\hline 1 & $0 \leq \mathrm{N} \leq 50$ & Tim yang Belum Berhasil \\
2 & $60 \leq \mathrm{N} \leq 150$ & Tim yang Baik (Good Team) \\
3 & $160 \leq \mathrm{N} \leq 200$ & Tim yang Baik Sekali (Great Team) \\
4 & $210 \leq \mathrm{N} \leq 300$ & Tim yang Istimewa (Super Team) \\
\hline
\end{tabular}

Tabel 5 Respons Siswa terhadap Model Permainan Geprek Kempung dan Gobag Sodor pada Kegiatan Uji Coba Kelompok Kecil

\begin{tabular}{clcc}
\hline \multirow{2}{*}{ No } & \multicolumn{1}{c}{ Kriteria Respons/Jawaban Siswa } & \multicolumn{2}{c}{ Persentase } \\
\cline { 3 - 4 } 1 & Sangat menarik, sangat jelas, dan sangat mudah & $85,71 \%$ & Geprek Sodor \\
2 & Menarik, jelas, dan mudah & $14,29 \%$ & $12 \%, 88 \%$ \\
3 & Cukup menarik, cukup jelas, dan cukup mudah & $0 \%$ & $0 \%$ \\
4 & Tidak menarik, tidak jelas, dan tidak mudah & $0 \%$ & $0 \%$ \\
\hline
\end{tabular}


gobag sodor dalam uji coba skala kecil dapat disimpulkan pada Tabel 5.

\section{Uji Coba Lapangan Kelompok Besar}

Setelah uji coba kelompok kecil, selanjutnya dilakukan uji coba lapangan kelompok besar, hal ini bertujuan untuk menemukan model permainan geprek kempung dan gobag sodor sebagai suatu model pembelajaran yang standar dan dapat diimplementasikan pada setiap kelas dengan kategori berbeda. Prosedur uji coba kelompok besar pada dasarnya sama dengan uji coba kelompok kecil, di samping dilakukan uji coba pembelajaran IPS menggunakan model permainan geprek kempung dan gobag sodor, juga dilakukan analisis respon siswa terhadap kedua model tersebut dan hasil pembelajaran yang berupa berupa soal tes.

\section{Tanggapan Siswa terhadap Model Permainan Tradisional Geprek Kempung}

Aspek tanggapan siswa terhadap penggunaan model permainan geprek kempung untuk pembelajaran IPS pada uji coba kelompok besar cukup beragam, bila dibandingkan uji coba kelompok kecil. Walau secara mayoritas siswa merespon positif terhadap semua asfek yang dinilai. namun ada 1 siswa $(2,70 \%)$ yang menjawab tidak menarik, tidak jelas, tidak paham, dan tidak mudah pada masing-masing aspek: (1) aspek kemenarikan model permainan geprek kempung untuk pembelajaran IPS; (2) aspek kepahaman siswa terhadap konsep materi yang disampaikan melalui model permainan geprek kempung; (3) tingkat kerumitan soal pada permaian geprek kempung; dan (4) aspek kepahaman siswa terhadap teknik penggunaan model permainan geprek kempung. Selebihnya, siswa menjawab cukup jelas, jelas dan sangat jelas. Secara keseluruhan respons siswa terhadap model permainan geprek kempung pada uji coba kelompok besar tertera sebagaimana Tabel 6.

\section{Tanggapan Siswa terhadap Model Permainan Gobag Sodor}

Respons siswa terhadap model permainan gobag sodor untuk pembelajaran IPS kelas IV materi Perkembangan Teknologi Produksi dan Komunikasi juga mendapatkan respon yang sangat positif dari siswa. Siswa sangat antusias mempraktekan model permainan ini. Hal ini terlihat jelas dari hasil jawaban angket yang dibagikan kepada siswa setelah belajar IPS menggunakan model permainan gobag sodor. Dari 37 responden hanya 1 siswa $(2,70 \%)$ yang menjawab tidak mudah pada aspek tingkat kerumitan soal dalam permaian gobag sodor. Selanjutnya, 1 siswa $(2,70 \%)$ yang menjawab cukup menarik model permainan gobag sodor untuk pembelajaran IPS, cukup paham terhadap konsep materi yang disampaikan melalui model permainan gobag sodor, cukup jelas gambar dan tulisan dalam media permainan gobag sodor, dan cukup jelas soal yang digunakan dalam media permainan gobag sodor. Bila dipersentasekan respon/jawaban siswa secara keseluruhan dari masing-masing aspek penilaian terhadap model permainan gobag sodor dapat dilihat pada Tabel 7.

\begin{tabular}{clc}
$\begin{array}{c}\text { Tabel } 6 \\
\text { Respons Keseluruhan Siswa terhadap } \\
\text { Model Permainan Geprek Kempung } \\
\text { pada Kegiatan Uji Coba Kelompok } \\
\text { Besar }\end{array}$ \\
\hline No & \multicolumn{1}{c}{$\begin{array}{c}\text { Kriteria Respons/Jawaban } \\
\text { Siswa }\end{array}$} & $\begin{array}{c}\text { Persen- } \\
\text { tase }\end{array}$ \\
\hline 1 & $\begin{array}{l}\text { Sangat menarik, sangat jelas, dan } \\
\text { sangat mudah }\end{array}$ & $44,60 \%$ \\
2 & $\begin{array}{l}\text { Menarik, jelas, dan mudah } \\
\text { Cukup menarik, cukup jelas, dan }\end{array}$ & $46,84 \%$ \\
3 & $\begin{array}{l}6,76 \% \\
\text { cukup mudah }\end{array}$ \\
4 & $\begin{array}{l}\text { Tidak menarik, tidak jelas, dan } \\
\text { tidak mudah }\end{array}$ & $1,80 \%$ \\
\hline
\end{tabular}

Tabel 7 Respons Keseluruhan Siswa terhadap Model Permainan Gobag Sodor pada Kegiatan Uji Coba Kelompok Besar

\begin{tabular}{|c|c|c|}
\hline No & $\begin{array}{c}\text { Kriteria Respons/Jawaban } \\
\text { Siswa }\end{array}$ & Persentase \\
\hline 1 & $\begin{array}{l}\text { Sangat menarik, sangat jelas, } \\
\text { dan sangat mudah }\end{array}$ & $66,66 \%$ \\
\hline 2 & Menarik, jelas, dan mudah & $31,09 \%$ \\
\hline 3 & $\begin{array}{l}\text { Kurang menarik, kurang jelas, } \\
\text { dan cukup mudah }\end{array}$ & $1,80 \%$ \\
\hline 4 & $\begin{array}{l}\text { Tidak menarik, tidak jelas, dan } \\
\text { tidak mudah }\end{array}$ & $0,45 \%$ \\
\hline
\end{tabular}

\section{Hasil Belajar Siswa}

Soal tes yang diberikan sebanyak 10 soal berupa pilihan ganda seputar materi Perkembangan Teknologi Produksi dan Komunikasi. Pada kegiatan uji coba kelompok kecil, dari 19 siswa 
yang mengikuti tes belajar, terdapat 2 siswa $(10,52 \%)$ yang tidak mengalami peningkatan maupun penurunan antara nilai pre-test dan posttes, selebihnya $(89,48 \%)$ mengalami peningkatan setelah belajar IPS menggunakan model permainan geprek kempung dan gobag sodor. Begitu pula dalam uji coba kelompok besar, dari 34 siswa yang mengikuti tes belajar, 5 siswa $(14,70 \%)$ tidak mengalami peningkatan maupun penurunan antara nilai pre-test dan post-test, 4 siswa $(11,77 \%)$ mengalami penurunan nilai tes belajar dan selebihnya 25 siswa $(73,53 \%)$ mengalami peningkatan setelah belajar IPS menggunakan model permainan geprek kempung dan gobag sodor. Untuk lebih jelasnya lihat Tabel 8. Sajian data nilai siswa hasil tes (pre-test dan post-test berupa soal pilihan ganda) pada kegiatan uji coba produk yang telah direkapitulasi disajikan pada Tabel 9.

Berdasarkan data tabel di atas, rata-rata hasil nilai pre-test dan post-test hasil belajar pada uji coba kelompok kecil dan kelompok besar menunjukan bahwa hasil nilai akhir (post-test) lebih besar dari pada hasil nilai awal (pre-test). Hal ini berarti terdapat perbedaan secara signifikan antara ratarata nilai awal sebelum penerapan model permainan geprek kempung dan gobag sogor dengan rata-rata nilai akhir sesudah penerapan model permainan geprek kempung dan gobag sogor. Dengan kata lain, mean score test kedua lebih besar dari pada mean score test pertama.

\section{PEMBAHASAN}

Secara konsepsional, mata pelajaran IPS dekat dengan lingkungan. Oleh karena itu, pembelajaran IPS khususnya di tingkat sekolah dasar (SD), seharusnya memanfaatkan secara optimal potensi lingkungan sebagai sumber belajar agar pembelajaran menjadi lebih bermakna, Ibrahim \& Sukmadinata (2010). Kenyataannya, hal ini belum dilakukan sepenuhnya oleh guru IPS SD. Pembelajaran IPS di SD cenderung tidak kontekstual. Potensi lingkungan setempat, khususnya budaya tradisional, belum dimanfaatkan guru secara optimal sebagai sumber belajar dalam proses pembelajaran. Pembelajaran lebih cenderung formal dan menegangkan, karena mengutamakan pengembangan aspek intelektual semata, dan buku teks pegangan guru menjadi sumber belajar utama.

Beberapa kesimpulan hasil penelitian terdahulu menunjukkan minimnya guru dalam menciptakan bahan ajar berupa model pembelajaran yang berbasis budaya lokal, yakni permainan tradisional. Penelitian terdahulu yang masih ada kaitannya dengan penelitian ini menyimpulkan bahwa guru IPS kurang kreatif dalam menciptakan bahan ajar yang berbasis budaya lokal, sehingga siswa kurang mengapresiasi budayanya sendiri (Pargito, 2000; Hadi, 1997; Rosmalah, 2003; Samion, 2002; dan Tukidjan, 2002). Guru cenderung berceramah sepanjang pembelajaran, sedangkan siswa disuruh menyalin dan menghafal bahan ajar. Belum ada satupun guru yang mencoba membuat model pembelajaran yang mengambil dari unsur kebudayaan tradisional. Bahkan sama sekali belum pernah dicoba pengintegrasian model permainan tradisional ke dalam pembelajaran IPS, kalaupun ada model permainan, bukan permainan yang bersumber dari kearifan lokal bangsa sendiri.

Berpangkal dari kondisi tersebut, perlu kiranya upaya pelestarian eksistensi permainan

Tabel 8 Hasil Belajar Siswa setelah Menggunakan Model Permainan Geprek Kempung dan Gobag Sodor

\begin{tabular}{lcc}
\hline \multirow{2}{*}{ Frekuensi hasil belajar } & \multicolumn{2}{c}{ Kegiatan Uji Coba } \\
\cline { 2 - 3 } & Kelompok Kecil & Kelompok Besar \\
\hline Meningkat & $89,48 \%$ & $73,53 \%$ \\
Tetap & $10,52 \%$ & $14,70 \%$ \\
Turun & - & $11,77 \%$ \\
\hline
\end{tabular}

Tabel 9 Rata-rata Nilai Hasil Belajar Siswa pada Kegiatan Uji Coba Lapangan

\begin{tabular}{lccc}
\hline \multicolumn{1}{c}{ Kegiatan Tes } & $\sum \mathbf{X}$ & N & Mean \\
\hline Pre Test Kelompok Kecil & 1040 & 19 & 54.7368 \\
Post Test Kelompok Kecil & 1610 & 19 & 84.7368 \\
Pre Test Kelompok Besar & 2190 & 34 & 64.4118 \\
Post Test Kelompok Besar & 2840 & 34 & 83.5294 \\
\hline
\end{tabular}


tradisional dan pengkajian yang lebih mendalam tentang manfaat yang dapat diperoleh melalui permainan tradisional, baik secara kognitif, psikologis, maupun sosial. Mengingat begitu pentingnya nilai budaya sebagai sumber belajar IPS, maka seharusnya hal ini ditindaklanjuti dengan membuat model pembelajaran berbasis budaya lokal yang di antaranya adalah permainan tradisional anak. Model pembelajaran ini sangat penting dikembangkan untuk menjadikan pembelajaran IPS lebih bermanfaat bagi siswa. Effendi (2011) berpendapat bahwa nilai budaya lokal khususnya kearifan lingkungan sangat penting untuk menjadikan pembelajaran IPS semakin bermakna. Senada dengan Efendi (2011) dan Ibrahim \& Sukmadinata (2010) menyatakan bahwa model pembelajaran IPS terpadu berbasis budaya yang dikembangkannya terbukti secara signifikan lebih efektif meningkatkan apresiasi siswa terhadap budaya lokal simultan dengan penguasaan materi pelajaran bila dibandingkan dengan model pembelajaran yang selama ini digunakan guru.

Permainan tradisional merupakan salah satu bentuk permainan yang mengandung banyak nilai universal dan nilai-nilai kearifan lokal (Gunawan, 2016). Kearifan lokal merupakan gagasan konseptual yang hidup dalam masyarakat, tumbuh dan berkembang secara terus-menerus dalam kesadaran masyarakat dari yang sifatnya berkaitan dengan kehidupan yang sakral sampai dengan yang profane (Gunawan, 2012). Kreativitas anak akan berkembang ketika guru menerapkan pembelajaran berbasis kearifan lokal (Gunawan, dkk., 2014). Nilai-nilai budaya lokal menjadi sumber belajar yang efektif dalam mengembangkan pembelajaran agar para siswa dekat dengan lingkungan dan budaya yang berkembang di masyarakat setempat (Gunawan dan Sulistyoningrum, 2013). Kepala sekolah memiliki peran yang strategis dalam membina guru agar dapat mengembangkan pembelajaran yang mampu mewariskan budaya lokal (Gunawan, 2015).

\section{SIMPULAN DAN SARAN}

\section{Simpulan}

Berdasarkan hasil uji coba lapangan, model permainan geprek kempung dan gobag sodor untuk pembelajaran IPS Kelas IV ini telah berhasil menunjukan kebermanfaatan yaitu dapat meningkatkan prestasi belajar siswa yang dapat dilihat dari hasil pencapaian siswa terhadap uji coba penguasaan materi (post-test). Berdasarkan nilai yang diperoleh siswa menunjukan bahwa pemahaman siswa terhada konsep IPS materi Perkembangan Teknologi Produksi dan Komunikasi dapat lebih baik dengan menggunakan model permainan geprek kempung dan gobag sodor.

Kelebihan dari model permainan tradisional geprek kempung dan gobag sodor untuk pembelajaran IPS ini, selain untuk menumbuh kembangkan unsur-unsur pendidikan yang telah disebutkan diatas, juga agar siswa lebih meningkatkan apresiasinya terhadap permainan tradisional, Tujuan ini jelas seirama dengan hakikat tujuan pembelajaran IPS yang sesungguhnya, yaitu terciptanya warga negara yang berbudi pekerti luhur mempunyai jiwa sosial yang tinggi. Oleh karena itu, model permainan tradisional geprek kempung dan gobag sodor dikembangkan ini sesuai dengan kebutuhan perkembangan kognitif, psikomotorik dan afektif siswa, seraya memanfaatkan sumber belajar yang berbasis kearifan lokal.

\section{Saran}

Berdasarkan kesimpulan, maka saran kepada guru lebih menekankan muatan belajarnya daripada muatan bermainnya, karena dalam hal ini konteksnya belajar sambil bermain bukan bermain sambil belajar. Saran kepada peneliti lain agar mengembangkan model permainan ini agar dimanfaatkan bukan hanya untuk pembelajaran IPS, namun semua mata pelajaran.

\section{DAFTAR RUJUKAN}

Brog, W. R., dan Gall, M. D. 1983. Educational Research: An Introduction. London: Longman, Inc.

Effendi, A. 2011. Implementasi Kearifan Lingkungan dalam Budaya Masyarakat Adat Kampung Kuta sebagai Sumber Pembelajaran IPS: Studi Etnografi pada Masyarakat Adat Kampung Kuta dan Kajian PTK di SMP Negeri 1 Tambaksari Kabupaten Ciamis. Tesis tidak diterbitkan. Bandung: Universitas Pendidikan Indonesia. 
Gunawan, I. 2012. Mengembangkan Karakter Bangsa Berdasarkan Kearifan Lokal. Prosiding Seminar Nasional Meretas Sekolah Humanis untuk Mendesain Siswa Sekolah Dasar yang Cerdas dan Berkarakter, Fakultas Keguruan dan Ilmu Pendidikan Universitas Muhammadiyah Surakarta, 6 Mei, hlm. 67 s.d. 79.

Gunawan, I. 2015. Pengaruh Kepemimpinan Transformasional dan Kepuasan Kerja terhadap Perilaku Kewargaan Organisasi Guru Sekolah Dasar. Premiere Educandum, $5(1), 59-81$.

Gunawan, I. 2016. Pasaran: Menggali Nilainilai Permainan Tradisional dalam Mengembangkan Sifat-sifat Kepemimpinan Pendidikan. Jurnal Studi Sosial, 8(1), 55-64.

Gunawan, I., dan Sulistyoningrum, R. T. 2013. Menggali Nilai-nilai Keunggulan Lokal Kesenian Reog Ponorogo Guna Mengembangkan Materi Keragaman Suku Bangsa dan Budaya pada Matapelajaran IPS Kelas IV Sekolah Dasar. Premiere Educandum, 3(1), 50-87.

Gunawan, I., Suraya, S. N., dan Tryanasari, D. 2014. Hubungan Kemampuan Berpikir Kreatif dan Kritis dengan Prestasi Belajar Mahasiswa pada Matakuliah Konsep Sains II. Premiere Educandum, 4(1), 1-32.

Hadi, N. 1997. Pemanfaatan Sumber Belajar oleh Guru dan Pengaruhnya terhadap Hasil Belajar dalam Pengajaran Pendidikan IPS (Studi Kasus di Kelas III SDN Kauman I dan SDN Kauman II Kotamadia Malang-Jawa Timur). Tesis tidak diterbitkan. Bandung: PIPS SPs UPI.
Hidayatullah, M. F. 2008. Mendidik Anak dengan Bermain. Surakarta: UNS Press.

Ibrahim, A., dan Sukmadinata, N. S. 2010 Pengembangan Model Pembelajaran Terpadu Berbasis Budaya. Jurnal Cakrawala Pendidikan, 19(2), 189-203.

Pargito. 2000. Pembelajaran IPS dengan Model Pengalaman Belajar di SD Daerah Pedesaan Tertinggal (IDT). Tesis tidak diterbitkan. Bandung: PIPS SPs UPI.

Rosmalah. 2003. Pemanfaatan Lingkungan sebagai Sumber Belajar dalam Pembelajaran Ilmu Pengetahuan Sosial di Sekolah Dasar Negeri Sumbersari Kota Malang. Tesis tidak diterbitkan. Malang: PPs Universitas Negeri Malang.

Samion, A. R. 2002. Pengembangan Kreativitas Mengajar Guru dalam Pembelajaran IPS di Sekolah Dasar. Disertasi tidak diterbitkan. Bandung: PIPS SPs UPI.

Tukidjan, E. 2002. Strategi Penyampaian Isi Pembelajaran Ilmu Pengetahuan Sosial di Taman Muda (Sekolah Dasar) Ibu Pawiyatan Taman Siswa Yogyakarta. Tesis tidak diterbitkan. Malang: PPs Universitas Negeri Malang. 